\title{
Image analysis of the size and morphological characteristics of ruminal digesta particles from sheep fed mixed-grass hay
}

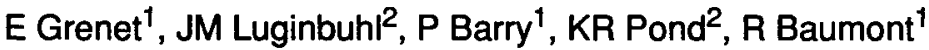 \\ 1 Station de Recherches sur la Nutrition des Herbivores, Unité Ingestion, INRA, Theix, \\ 63122 Ceyrat, France; ${ }^{2}$ North Carolina State University, Raleigh, 27695-7621 NC, USA
}

Introduction - The reduction of feed into small particles is an essential process in mastication and digestion. Traditionally, particle size has been evaluated by sieving. Image analysis allows a precise assessment of particle length, width, area and shape. This technique was used to measure digesta particles taken from the rumen of sheep.

Materials and Methods - A mixed-grass hay harvested in early bloom ( $63.5 \% \mathrm{NDF}$ ) was fed ad libitum (10\% refusals), at 08:00 and 16:00, to 3 ruminally cannulated sheep. Ruminal content was evacuated by hand $2 \mathrm{~h}$ after the evening feeding, mixed, sampled and returned to the animals. Samples of ruminal contents were separated by wet sieving and the particles retained on the top 2 sieves ( 8 and $4 \mathrm{~mm}$ mesh) were spread on moist filter papers and photo- graphed. The photographs were then scanned by image analysis (Luginbuhl, 1987).

Results and Discussion - The particles retained on each sieve were approximately 1.5-2 times longer than the sieve mesh (table I) and within each sieve variation was large. The distribution was not normal. Image analysis provided unique information on the morphological characteristics of feed particles. The length/width ratio decreased by $32.2 \%$ on the $4 \mathrm{~mm}$ sieve, indicating that smaller particles were rounder. In addition, these results indicated that sieve aperture and particle size are different.

Luginbuhl JM (1987) PhD Dissertation, North Carolina State University, Raleigh, NC, USA

Table I. Dimensions of ruminal particles from 3 sheep fed mixed-grass hay a.

\begin{tabular}{|c|c|c|c|c|c|c|c|c|}
\hline \multicolumn{2}{|c|}{ Sieve aperture ( $\mathrm{mm}$ ) } & \multicolumn{3}{|l|}{8} & \multicolumn{4}{|c|}{4} \\
\hline \multirow[t]{2}{*}{ No of particles } & \multicolumn{4}{|c|}{609} & \multicolumn{4}{|c|}{776} \\
\hline & $x^{b}$ & range & $\mathbf{s}^{b}$ & $k^{b}$ & $x^{b}$ & range & $\mathbf{s}^{b}$ & $\mathrm{k}^{b}$ \\
\hline $\begin{array}{l}\text { Area }\left(\mathrm{mm}^{2}\right) \\
\text { Perimeter }(\mathrm{mm}) \\
\text { Form factor c } \\
\text { Length }(\mathrm{mm}) \\
\text { Width }(\mathrm{mm}) \\
\text { Length/width }\end{array}$ & $\begin{array}{r}13.4 \\
26.5 \\
0.4 \\
11.1 \\
1.4 \\
8.2\end{array}$ & $\begin{array}{l}0.6-101.7 \\
2.2-132.4 \\
0.1-\quad 1.0 \\
1.1-54.3 \\
0.6-\quad 4.8 \\
1.1-33.8\end{array}$ & $\begin{array}{l}2.6 \\
1.6 \\
1.3 \\
1.4 \\
2.0 \\
1.3\end{array}$ & $\begin{array}{l}9.2 \\
4.1 \\
0.6 \\
2.9 \\
5.9 \\
2.4\end{array}$ & $\begin{array}{r}10.5 \\
19.5 \\
0.4 \\
8.0 \\
1.5 \\
5.6\end{array}$ & $\begin{array}{l}0.6-66.2 \\
2.2-102.4 \\
0.1-1.0 \\
1.1-62.2 \\
0.7-5.2 \\
0.8-26.8\end{array}$ & $\begin{array}{l}2.0 \\
1.5 \\
1.1 \\
1.0 \\
1.6 \\
1.2\end{array}$ & $\begin{array}{l}6.4 \\
5.0 \\
0.2 \\
3.9 \\
3.5 \\
3.2\end{array}$ \\
\hline
\end{tabular}

a Ruminal contents were evacuated by hand $2 \mathrm{~h}$ after the evening feeding. ${ }^{\mathrm{b}} \mathrm{X}$ mean; $s=$ skewness; $k=$ kurtosis.

c Equal to 1 for a perfect circle and decreasing as particle irregularity increases. 